\title{
¿Gentrificación comercial en contexto de superdiversidad?: La transformación del comercio local en el centro y pericentro de Santiago de Chile
}

Commercial gentrification in the context of super-diversity? The transformation of local streets shops in Santiago de Chile, downtown and pericenter

\author{
René Catalán Hidalgo \\ Facultad de Humanidades, Universidad de Santiago, Santiago, Chile
}

rene.catalan@usach.cl

\section{Resumen}

Esta investigación se enfoca en las transformaciones materiales de los espacios comerciales del centro y pericentro de la ciudad de Santiago de Chile. Su foco específico es el proceso conjunto de gentrificación comercial y superdiversificación, los que configuran la geografía específica de la transformación que produce la gentrificación en Santiago. Se emplean con este fin dos herramientas analíticas, primero un Indicador de Potencial de Gentrificación el que permitió seleccionar las zonas con mayor potencial de gentrificación. Posteriormente, un análisis visual permitió analizar las transformaciones recientes de los espacios comerciales. En base a ambos análisis se lograron identificar seis tendencias que han ido transformando el centro de la ciudad. Estos cambios expresan el efecto conjunto de gentrificación comercial y superdiversidad, y muestran el carácter particular de la transformación urbana que esta experimentado la ciudad de Santiago y aportan una perspectiva distinta para el estudio de la gentrificación.

\begin{abstract}
This research focuses on the material transformations of the local street shops in Santiago de Chile downtown and pericenter. Its focus is on the joint process of commercial gentrification and super-diversity, which can configure the specific geography of the transformation that gentrification is producing in Santiago. Two analytical tools are used: firstly, a Gentrification Potential Indicator for selecting the areas with the highest gentrification potential. Subsequently, a visual analysis allows us to understand the recent transformations of local street shops. Six trends that have been transforming local street shops were identified. These changes express the joint effect of commercial gentrification and superdiversity and show the particular character of the urban transformation that Santiago is undergoing and provide a different perspective for the study of gentrification in Santiago.

Keywords: gentrification, commercial gentrification, migration, super-diversity, urban transformation.
\end{abstract}

Palabras claves: gentrificación, gentrificación comercial, migración, superdiversidad, transformación urbana.

Documento recibido el 31 de agosto de 2019 y aceptado el 27 de abril de 2020.

Esta investigación contó con financiamiento del Núcleo de Investigación Barrio y Ciudad (NuBAC) del Instituto de Estudios Urbanos y Territoriales de la Pontificia Universidad Católica de Chile.

Este artículo participó en el Seminario Internacional "El Complejo Urbano Financiero-Inmobiliario en América Latina", realizado el jueves 4 y viernes 5 de abril de 2019, en Santiago de Chile, organizado y patrocinado en el marco del Proyecto Fondecyt Regular 1151287 - Investigador Principal: Ernesto López Morales, el Centro de Estudios del Conflicto y la Cohesión Social (COES), la Facultad de Arquitectura y Urbanismo de la Universidad de Chile y su Doctorado en Territorio, Espacio y Sociedad (D_TES).

Cómo citar: Catalán Hidalgo, R. (2020). ¿Gentrificación comercial en contexto de superdiversidad?: La transformación del comercio local en el centro y pericentro de Santiago de Chile. Revista de Urbanismo, 42, 52-71. https://doi.org/10.5354/0717$\underline{5051.2020 .54281}$ 
El presente estudio se enmarca en los estudios de la gentrificación, específicamente de la gentrificación comercial, y busca introducirse en la comprensión de este fenómeno a partir de la particularidad geográfica de la ciudad de Santiago de Chile.

La globalización de fenómeno de la gentrificación (Smith, 2002) ha enfrentado a los investigadores a la necesidad paralela de cuestionarse este concepto, es por eso que se hace necesario interrogarse por las particularidades de este fenómeno en el contexto de Santiago, donde el proceso de gentrificación que ha sido impulsado gracias a la intervención de los agentes inmobiliarios y al impulso que ellos han tenido desde la institucionalidad política (Casgrain y Janoschka, 2013; López-Morales, 2013), sino también que debe ser comprendido en conjunto con procesos paralelos de transformación urbana, como es la creciente llegada de población migrante a la ciudad, de ahí que se proponga introducirse el enfoque de la superdiversidad, para comprender la transformación urbana desde una perspectiva que se haga cargo de su complejidad.

Esta investigación además propone un contexto urbano específico: el comercio local. Primero, porque este aspecto de la gentrificación ha sido menos abordado dentro de los estudios urbanos (Rojo, 2016), pero sobre todo, porque se estima que este contexto permite indagar de mejor forma la transformación conjunta que produce la gentrificación comercial y la superdiversidad en el contexto urbano, a la luz de trabajos recientes en ciudades cosmopolitas como Nueva York, Londres, Ámsterdam, Shanghái, Berlín y Tokio (Zukin, Kasinitz \& Xiangming, 2016).

La pregunta que guía este trabajo entonces es: ¿cómo se transforma el entorno construido en los espacios comerciales de los barrios con alto potencial de gentrificación y con alta migración transnacional en la ciudad de Santiago, en un contexto de superdiversidad?

Con este objetivo es que se proponen dos herramientas analíticas para introducirse en estos fenómenos. Primero, un análisis espacial en base a un índice de Potencial de Gentrificación, el que permite tratar con este proceso a nivel metropolitano. A partir de este análisis se realiza la selección de las zonas de la ciudad con mayor potencial de gentrificación, zonas en las que se realiza el segundo análisis. Este análisis permite graficar y comprender, mediante el uso de imágenes, el cambio que se ha ido produciendo en los últimos años en el entorno construido y que ha ido dando forma al Santiago contemporáneo.

\section{Descolonizando el concepto de Gentrificación}

El concepto original de gentrificación acuñado por Glass (1964) para la ciudad de Londres, expresaba el asentamiento de grupos medios hacia las áreas centrales deterioradas de la ciudad, lo que implicaba tanto renovación o rehabilitación de los barrios y sus viviendas, y el desplazamiento de la población. Con algunos matices, este modelo original se fue expandiendo y se utilizó para comprender procesos similares en el resto de Europa, Estados Unidos y en países del Sur Global, la gentrificación se había convertido en un fenómeno global (Smith, 2002).

Más recientemente, Clark ha definido el fenómeno como "la reestructuración espacial del área urbana por inyección de capital fijo en el mercado inmobiliario y de infraestructura, orientada al reemplazo de usuarios de ingresos medios-bajos por usuarios de poder económico superior, en contexto de mercantilización del suelo" (2005, p. 263).

Sin embargo, la globalización de este fenómeno ha enfrentado a los investigadores a la necesidad paralela de cuestionarse este concepto. Lees $(2000,2012)$ es quien realiza los primeros llamados en contra del uso de conceptos globales sin atención a su especificidad geográfica, a lo que denomina "urbanismo imitativo". Para el caso latinoamericano, la misma autora en conjunto con López-Morales y Shin (2016) han analizado las características del fenómeno para el contexto local, lo cual les ha permitido afirmar que existe una geografía particular de la gentrificación en América Latina.

Para el caso chileno en particular, López-Morales (2013) plantea que la gentrificación estaría garantizada por un recambio a gran escala, con considerable altura y densidad, del stock edificado residencial; proceso que es dominado por agentes productores y no por residentes, lo cual marca una diferencia importante respecto al contexto europeo y norteamericano (Casgrain y Janoschka, 2013). 


\section{Gentrificación comercial como acceso a la transformación de la cotidianidad}

Las conceptualizaciones presentadas sin embargo, no abordan la especificidad cotidiana del fenómeno, reflejada en un ámbito clave como el del consumo cotidiano, es por eso que se propone el concepto de "gentrificación comercial" para analizar la transformación desde la perspectiva de los espacios comerciales del barrio (Gonzalez \& Waley, 2013; Hubbard, 2017; Zukin, 2010; Zukin et al., 2016), concepto que, como ha mostrado Rojo (2016), ha tenido un abordaje menor en los estudios urbanos y del estudio de la gentrificación.

Marcuse (1985) en su texto clásico sobre el desplazamiento entrevé este proceso de gentrificación comercial, haciendo referencia al desplazamiento por condiciones externas a la vivienda misma y que se centra en el barrio y su encarecimiento, impactando en el consumo debido al alza de los precios en las tiendas del sector o la aparición de nuevas tiendas enfocadas en una clientela distinta a la que habitualmente vive en el barrio.

Para comprender la gentrificación comercial es clave el concepto de acumulación por desposesión del hábitat de Janoschka (2016), quien lo propone como una expansión de la desposesión por acumulación propuesta por Harvey (2005). La acumulación por desposesión del hábitat opera a un nivel económico, donde se inserta Harvey; un nivel político, por la labor directa o indirecta del Estado; además de un nivel simbólico y uno psicológico. Son estos dos últimos niveles los que marcan la diferencia al hablar de gentrificación comercial.

Como proceso simbólico, el desplazamiento expresa la reconfiguración de los espacios urbanos mediante su homogeneización, el cual expresa una pugna por la hegemonía cultural de estos espacios. La consideración simbólica del desplazamiento va muy a la par de la consideración psicológica, ya que el cambio simbólico impacta a nivel individual en forma de alienación de los habitantes, quienes experimentan una pérdida de lugar (Janoschka, 2016). Son estas dimensiones del desplazamiento, simbólica y psicológica, las que permiten una mejor comprensión de la gentrificación comercial y de la gentrificación como un proceso totalizador que opera a diferentes niveles y que supera los límites de la residencia.

Por su parte, González y Waley (2013) distinguen tres características del proceso de gentrificación comercial: la privatización y comodificación de las zonas centrales de la ciudad, el desplazamiento de los consumidores habituales y la transformación de estas zonas en una experiencia de consumo, mediante la fetichización de la comida y la oferta de un espacio sanitizado y comodificado. Hubbard (2017), en tanto, conceptualiza a este proceso como un blanqueamiento (el paso del cuello azul o blue collar, de la clase trabajadora, al cuello blanco o white collar de la clase media profesional) y como una limpieza de clase de los espacios comerciales del barrio, transformación que no sólo es cultural, sino también de clase.

En síntesis, se puede ver cómo es que el desplazamiento producido por la gentrificación comercial se vuelve crítico en el espacio del urbano, cuando entendemos con Zukin (2008) que la compra y el consumo en general, son la fuente principal de ciudadanía y de expresión creativa de la sociedad contemporánea.

\section{Superdiversidad y el desafío de comprender las transformaciones urbanas desde la complejidad}

Uno de los conceptos claves para la compresión de la diversidad es el de multiculturalismo, el cual grafica el pluralismo presente en la ciudades, principalmente del Norte Global, gatillado por las importantes olas migratorias vinculadas con la caída de los diferentes colonialismos, y los grandes procesos migratorios motivados por causas humanitarias o económicas (Yanasmayan, 2011).

El concepto de superdiversidad (Vertovec, 2007) emerge entonces para complejizar esta forma de entender la diversidad. La emergencia de este concepto tiene como hito clave, la publicación por la Alcaldía de Londres de un análisis de los resultados del Censo de 2001 bajo el titulo The World in One City (El Mundo en Una Ciudad). Este análisis establecía la presencia de 179 nacionalidades en la ciudad, situándola como la ciudad con mayor multiculturalidad del mundo (Freedland, 2005). Si replicásemos este análisis en la ciudad de Santiago, tendríamos que en 2017 vivían en ella personas 
provenientes de al menos 67 países $^{1}$ (INE, 2017b). Desde la perspectiva de la multiculturalidad, esta cifra nos pondría lejos de la realidad londinense, ya que representa cerca de un tercio de la multiculturalidad registrada en Londres; sin embargo, el considerar la diversidad desde la superdiversidad permite interrogarnos sobre la diversidad étnica en el contexto de complejidad que Santiago ofrece.

El concepto de superdiversidad expresa la necesidad de abordar la diversidad más allá del habitual contexto étnico desde el que se la aborda. Desde esta perspectiva, el estudio de la diversidad debiera considerar una serie de variables adicionales como son los estatus legales migratorios, por los derechos y restricciones que ellos generan; las estrategias diversas de inserción en el mercado laboral; otros elementos propios de la interacción cotidiana como son el género, las relaciones intergeneracionales, las diferencias a nivel de capital cultural, entre otros factores.

Desde una formulación más reciente, Wessendorf describe la superdiversidad:

Caracterizada no sólo por una multiplicidad de diferentes minorías étnicas y de migrantes, sino que también por la diferenciación en términos de la historia de la migración, los antecedentes educacionales, la religión, el estatus legal, largo de la residencia y los antecedentes económicos, entre las minorías étnicas y los migrantes, así como de la población blanca británica. (Wessendorf, 2014, p. 1)

Lo interesante de esta formulación es que va más allá del contexto migratorio, incluyendo a la población inglesa blanca dentro de su conceptualización, expandiendo los límites del concepto. Hiebert, Rath, \& Vertovec (2015), en tanto, proponen una geografía del concepto, estableciendo una diferencia entre el Norte y el Sur Global:

En los países más desarrollados estamos acostumbrados a pensar en que quienes llegan a la ciudad se asientan primero en los espacios

\footnotetext{
1 Las cifras del Censo 2017 sobre países de origen, agrupan por continente a los países con menor cantidad de migrantes.

2 De acuerdo con los datos aportados por el INE, el porcentaje de migrantes internacionales en Chile pasó del 0,8\% en 1992 al 1,3\% en
}

deteriorados del centro. Pero el proceso conjunto de gentrificación y migración en masa [del Sur Global] ha cambiado profundamente la geografía de los asentamientos migrantes, el que es principalmente un fenómeno suburbano. (Hiebert et al., 2015, p. 14)

A diferencia de lo que ocurrió en el Norte Global, en el Sur Global los procesos masivos de migración, como el que atraviesa Chile en la actualidad, ${ }^{2}$ se entremezclan con procesos de gentrificación del centro de la ciudad. Los migrantes de esta región no tienen asegurados espacios específicos del centro de la ciudad como espacio de asentamiento, debiendo disputarlos con los grupos medios que vuelven a vivir al centro de la ciudad (Hiebert et al., 2015; Wessendorf, 2014).

Frente a este proceso de transformación urbana atravesado por la superdiversidad, los estudios recientes sobre gentrificación en Santiago de Chile (Janoschka, 2016, 2016; López-Morales, 2013, 2015; López-Morales et al., 2016; Sabatini et al., 2017) no han abordado el factor migración para comprender el panorama completo de estos cambios urbanos, situándose mayormente desde la oposición entre dos grupos en conflicto, es decir, entre migrantes transnacionales y la población "autóctona" del barrio, o entre esta última y los gentrificadores.

Desde el estudio de la gentrificación comercial en tanto, la escasa investigación existente tampoco aborda el efecto conjunto de ambos procesos, limitándose a analizar la activación y renovación de los espacios comerciales (Colodro, 2017) o a replicar la lógica del desplazamiento de los espacios residenciales a los espacios comerciales (Rivera y Orozco, 2014).

De esta forma entonces es que emerge la pregunta que guía esta investigación: ¿cómo se transforma el entorno construido en los espacios comerciales de los barrios con alto potencial de gentrificación y con alta migración transnacional en la ciudad de Santiago, en un contexto de superdiversidad?

2002, Ilegando en 2017 al 4,4\%. Cifra que para la Región Metropolitana representó un $7 \%$ (INE, 2018). 


\section{El comercio migrante como espacio de pertenencia}

Los espacios comerciales, más allá de la transacción económica, son espacios de sociabilidad (Gonzalez, 2017; We Made That LSE Cities, 2017):

Las interacciones entre emprendedores y consumidores en los mercados callejeros son públicas. Los consumidores presencian transacciones y aprenden los hábitos/el habitus de el mercado en una especie de teatro público [...] La información sobre los precios es comunicada en público y los códigos de conducta son transmitidos de vendedor a vendedor y de consumidor a consumidor. (Hiebert et al., 2015, p. 10)

Los espacios comerciales emergen como lugares en que significados y prácticas son transmitidos e incorporados (Zukin, 2005). Esta capacidad de conexión no sólo refiere a significados y prácticas propias del contexto, los espacios comerciales además tienen la capacidad de conectar con espacios que están más allá, en lo que Doreen Massey ha denominado "sentido global de espacio" (citada en Hall, Finlay, \& King, 2018). Este carácter translocal de estos espacios es fundamental cuando analizamos los espacios comerciales ligados con la migración.

Al encontrarse en un contexto nacional distinto, las tiendas de migrantes transnacionales son espacios claves para la construcción de "pertenencia" en las comunidades de migrantes, ya que ellas posibilitan la sensación de “estar en casa” (Hall, 2009).

Un elemento adicional a la hora de analizar el comercio migrante es que éste no sólo se da en el marco del comercio formal, acotado al espacio específico de una tienda, éste también se constituye en espacios informales dentro del espacio de la calle. Esto se produce gracias a las bajas barreras de ingreso que presentan los espacios comerciales. El comercio informal, además, no sólo flexibiliza las barreras normativas, sino también las barreras idiomáticas, educacionales y de capacitación (Hiebert et al., 2015). El comercio entonces, sea formal o informal, gracias a su capacidad de comprimir el tiempo y el espacio, permite el entrecruce de personas con orígenes y culturas distintas, en un mismo lugar, siendo la forma principal mediante la cual lo global puede insertarse en lo local (Hiebert et al., 2015, p. 17).

\section{Espacios comerciales como espacios para la superdiversidad}

Los espacios comerciales emergen como lugares de encuentro entre la sociedad y la economía, en donde la diversidad se intersecta $y$ donde personas con características muy dispares no sólo se encuentran, sino que además se coordinan (Hiebert et al., 2015). Las bajas barreras de entradas en términos económicos, sociales y culturales facilitan la participación de la población migrante que se ha vuelto vulnerable producto del propio movimiento migratorio, viendo dificultada su completa inclusión es las diferentes esferas sociales.

Estas características de los espacios comerciales nos permiten entenderlos como lugares en donde se desarrolla la pertenencia en contextos marcados por la diversidad (Hall, 2009, 2012, 2013). Desde esta perspectiva entonces son un contexto clave para el estudio de la superdiversidad gracias a sus características particulares que le dan elementos de "universalidad" a este tipo de espacios alrededor del mundo.

Frente a estas características universales de los espacios comerciales, cabe preguntarse por las particularidades que emergen en el contexto de una ciudad como Santiago y que le otorgan características distintas a la superdiversidad derivada de sus procesos migratorios recientes.

\section{Diseño metodológico}

Dado que el objetivo transversal fue estudiar la transformación de espacios comerciales a nivel material, se empleó una metodología mixta para captar los diferentes aspectos de las transformaciones urbanas (Hwang \& Sampson, 2014; Loukaitou-Sideris et al., 2017; We Made That LSE Cities, 2017).

Las técnicas de análisis empleados corresponden a un análisis espacial, realizado en base al Indicador de Potencial de Gentrificación (IPG), indicador creado para estos efectos y que permitió identificar las zonas de estudios, y un análisis visual utilizado para captar las transformaciones del entorno construido dentro de las zonas seleccionadas. Ambas técnicas buscaban ocupar información disponible a nivel nacional, de modo tal que fuese posible replicar este análisis en otras ciudades chilenas. 


\section{Identificación de zonas}

Al ser la superdiversificación un concepto complejo y multivariable, la definición de la zona en donde se realizó el análisis posterior se hizo de forma deductiva, mediante la identificación espacial de los dos fenómenos que la caracterizan en el contexto de Sur Global: gentrificación y migración (Hiebert, Rath, \& Vertovec, 2015). Para ello se construyó el IPG a nivel de la Región Metropolitana de Santiago, el que luego fue contrastado con el porcentaje de migración presente en las zonas identificadas mediante el IPG, el cual debía ser significativamente mayor al 7\% regional (INE, 2017b). De este modo, ambos parámetros permitieron realizar la selección.

Tabla 1

Operacionalización Indicador de Potencial de Gentrificación

\begin{tabular}{|c|c|c|c|c|}
\hline Índice & Subíndice & Variable(s) & Período & Fuente \\
\hline \multicolumn{2}{|c|}{ Rejuvenecimiento } & Edad jefa(e) de hogar & $2002-2017$ & Censo de Población y Vivienda 2017 \\
\hline \multirow[t]{7}{*}{$\begin{array}{l}\text { Índice Socio Material } \\
\text { Territorial }\end{array}$} & \multirow[t]{2}{*}{$\begin{array}{l}\text { Aumento de la } \\
\text { escolaridad }\end{array}$} & $\begin{array}{l}\text { Curso o año más alto } \\
\text { aprobado }\end{array}$ & & $\begin{array}{l}\text { Censo Nacional de Población y de } \\
\text { Vivienda } 2002\end{array}$ \\
\hline & & $\begin{array}{l}\text { Nivel del curso más alto } \\
\text { aprobado }\end{array}$ & & \\
\hline & \multirow[t]{3}{*}{$\begin{array}{l}\text { Mejora en el Índice de } \\
\text { Materialidad }\end{array}$} & $\begin{array}{l}\text { Material de los muros } \\
\text { exteriores }\end{array}$ & & \\
\hline & & $\begin{array}{l}\text { Material en la cubierta del } \\
\text { techo }\end{array}$ & & \\
\hline & & $\begin{array}{l}\text { Material de construcción del } \\
\text { piso }\end{array}$ & & \\
\hline & \multirow{2}{*}{$\begin{array}{l}\text { Disminución del } \\
\text { hacinamiento }\end{array}$} & Cantidad de personas & & \\
\hline & & $\begin{array}{l}\text { Número de pieza usadas } \\
\text { exclusivamente como } \\
\text { dormitorio }\end{array}$ & & \\
\hline \multicolumn{2}{|l|}{ Densificación } & Cantidad de personas & & \\
\hline \multicolumn{2}{|c|}{ Aumento Valor del Suelo } & Valor del suelo & 2012-2017 & $\begin{array}{l}\text { Observatorio de Ciudades UC, en base a } \\
\text { información del Servicio de Impuestos } \\
\text { Internos }\end{array}$ \\
\hline \multicolumn{2}{|c|}{ Altura máxima en las edificaciones } & Número de pisos & 2012-2017 & \multirow{2}{*}{$\begin{array}{l}\text { Permisos de Edificación, Instituto } \\
\text { Nacional de Estadísticas }\end{array}$} \\
\hline \multicolumn{2}{|c|}{ Edificaciones de uso mixto } & Destino & 2012-2017 & \\
\hline
\end{tabular}

Respecto a la temporalidad de este análisis, se consideraron 5 años en base a la pregunta censal “¿En qué comuna o país vivía en abril de 2012 ?" (INE, 2017a). ${ }^{3}$

Cabe señalar, que el IPG busca expresar la transformación en los diferentes territorios del Gran Santiago, por ende, el cálculo considera la variación porcentual dentro del período seleccionado, por lo que un número más alto en cualquiera de las dimensiones, indica una mayor variación entre ambos períodos y no una magnitud mayor del fenómeno medido.

\section{Operacionalización del Indicador de Potencial de Gentrificación}

La operacionalización del IPG entonces, quedó expresada en la Tabla 1 la que muestra sus seis dimensiones, además de los indicadores utilizados y sus fuentes respectivas.

Fuente: elaboración propia.

\footnotetext{
${ }^{3}$ Este período se aumento a 15 años para el caso de la información censal, 2002-2017, debido a las limitaciones del Censo 2012 (Contraloría General de la República, 2014).
} 


\section{Rejuvenecimiento}

En base a la edad de la jefa o jefe de hogar, se calculó la variación negativa del promedio de edad, esto es, el cómo este disminuye entre ambos censos. Capturar el rejuvenecimiento permite dar cuenta de la llegada de nuevos grupos medios, caracterizados por su menor edad relativa.

\section{Índice Socio Material Territorial (ISMT)}

Este índice se construyó en base a la metodología utilizada por el Observatorio de Ciudades de la Pontificia Universidad Católica de Chile (OCUC). EI ISMT busca "reconocer que la construcción social del territorio y su materialidad resultan de una dialéctica socio-espacial donde se reconoce que el componente social estructura los territorios, al mismo tiempo que los territorios dan forma a la sociedad" (Observatorio de Ciudades UC, s. f.). Este índice además permitió condesar tanto la mejora en las condiciones de habitabilidad de los hogares, como el nivel socioeconómico de estos mismos.

Para el cálculo del ISMT se emplearon tres subíndices construidos en base a siete variables censales.

Índice de escolaridad. La escolaridad se mide en años de escolaridad, mediante la combinación de dos variables censales, que son el último año o curso aprobado y el nivel educacional correspondiente, combinación que permitió calcular una variable continua.

Índice de materialidad. Este índice se compone de tres variables que recogen la materialidad del piso, el techo y las paredes de la vivienda, las cuales se categorizan en base a los criterios utilizados por la Encuesta de Caracterización Socioeconómica (Casen) del Ministerio de Desarrollo Social, en tres niveles: aceptable, recuperable e irrecuperable (Observatorio Social, 2017).

Índice de hacinamiento. ${ }^{4}$ Este índice permitió calcular la cantidad de piezas de la vivienda con uso exclusivo para dormitorio, respecto al total de personas del hogar que viven en ella. En base a este cálculo se categoriza el hacinamiento en tres niveles: sin hacinamiento,

\footnotetext{
${ }^{4}$ Se excluyeron del análisis las viviendas colectivas, las viviendas móviles
} y la población en situación de calle. Estas últimas se excluyen debido a hacinamiento medio y hacinamiento crítico (Observatorio Social, 2017).

Densificación. La densificación se expresó geométricamente, como la cantidad de habitantes por hectárea.

Aumento del valor del suelo. El valor del suelo se obtuvo a partir de la información dispuesta por el Servicio de Impuestos Internos (SII) y catalogada por el OCUC. También se emplearon estimaciones realizadas por el mismo OCUC.

Altura máxima en las edificaciones. La altura máxima de los permisos de edificación otorgados permite vincular la densificación del territorio con la forma del entorno construido e integrar los instrumentos de planificación territorial dentro del índice, bajo el supuesto de que, al considerar permisos de edificación otorgados, esto se ajusta a la normativa correspondiente.

Edificaciones de uso mixto. Igualmente, el destino de uso de las edificaciones autorizadas permitió captar el uso mixto del espacio urbano, característico también de los espacios que atraviesan procesos de gentrificación.

\section{Identificación de zonas: Análisis espacial.}

En esta etapa se utilizó el análisis estadístico espacial denominado "Indicador Local de Asociación Espacial"5 (Anselin, 2010), el cual permite reconocer el agrupamiento de unidades territoriales en base a una variable específica (Andresen, 2011; Moons, Brijs \& Wets, 2008).

Cada uno de los seis indicadores sirvieron de suministro para realizar un análisis LISA parcial y la superposición de cada uno de estos análisis permitió calcular un índice sumatorio con valores que van entre el 0 y el 6, en base a los valores High-High. Es decir que, a mayor valor del IPG existe un mayor potencial de gentrificación de la zona. que se trata de ocupaciones espaciales transitorias, sin una sujeción territorial clara y duradera.

${ }^{5}$ LISA, por sus siglas en inglés 


\section{Cambio en los aspectos materiales de los espacios comerciales}

Los cambios en los aspectos materiales y simbólicos de la zona seleccionada fueron abordados mediante un análisis visual. Tras la selección de la zona se fotografiaron las fachadas de los todos los espacios comerciales -comercio establecido- de la zona seleccionada. Posteriormente, estas imágenes fueron contrastadas con el registro histórico dispuesto en la plataforma Google Street View (GSV) de Google, análisis comparativo que toma como referencia el trabajo de Hwang \& Sampson (2014).

El uso de este análisis permitió que las características identificadas a partir del registro in situ fuesen contrastadas, además de identificar las transformaciones de los espacios comerciales de la zona seleccionada, expresada en la materialidad de sus espacios comerciales.

\section{Selección de las zonas.}

Cada uno de los seis índices construidos sirvieron de suministro para realizar un análisis LISA parcial, lo que permitieron identificar cómo forman clústeres cada una de las variables del estudio en la ciudad de Santiago. Los clústeres identificados por la alta concentración del fenómeno analizado (High-High) sirven de insumo para la sumatoria de condiciones, la que opera como un índice que va del 0 al 6 , donde la sumatoria implica la superposición de las áreas definidas por los análisis LISA.

A esta suma de condiciones, además, se le agregaron dos condicionantes claves para captar con mayor precisión el potencial de transformación mediante gentrificación del territorio. La primera es la variación positiva de la escolaridad, esto es, que el promedio de años de educación de cada zona aumente dentro del período. Se utiliza la educación como mejor proxy para establecer los ingresos, según lo que establece la Función de Mincer (Mincer, 1974), y así captar la llegada de grupos de mayores ingresos al barrio, de acuerdo con el concepto de gentrificación empleado.

La segunda condición es la densificación, clave también en la caracterización del fenómeno para el caso chileno, de una gentrificación mediada por el desarrollo inmobiliario (López-Morales, 2013).

De este modo, la sumatoria de condiciones va de 3 a 6 , como se aprecia en la Figura 1.

\section{Figura 1}

\section{Delimitación de zonas que cumplen con el número mínimo de condicionantes}

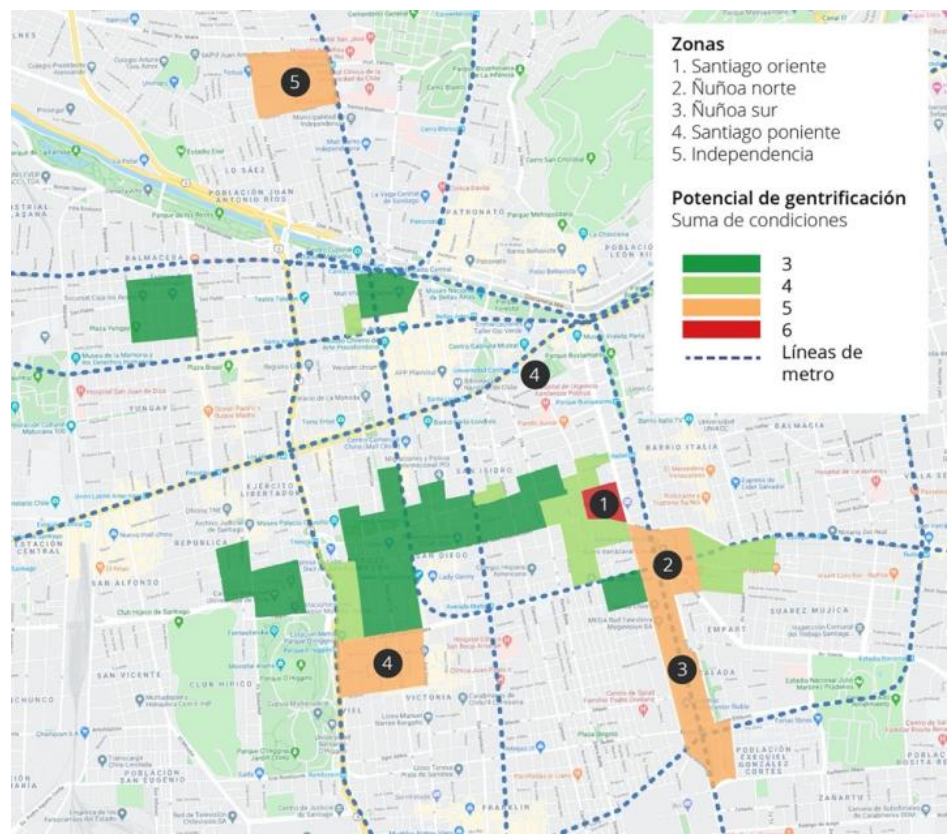

Fuente: Elaboración propia en base a los Censos de Población y Vivienda 2002 y 2017 del Instituto Nacional de Estadísticas, la base de Permisos de Edificación 2012 a 2017 del Instituto Nacional de Estadísticas y la Estimación del Valor del Suelo realizada por el Observatorio de Ciudades UC. 


\section{Análisis del contexto (Santiago)}

Lo primero que se aprecia es que todas las zonas identificadas a través del IPG se encuentran en Santiago Centro o en comunas aledañas, como son Independencia al norte y Providencia y Ñuñoa al oriente. Un gran clúster de zonas se desarrolla en torno al eje Santa Isabel, el que además se extiende hacia el sur por Vicuña Mackenna y
Gran Avenida. Adicionalmente, se pueden ver tres zonas aisladas, una en torno a la Estación del Metro Cal y Canto, otra al norte del Barrio Yungay en torno a la Estación del Metro Cumming y la última en Independencia, al poniente de la Estación del Metro Hospitales. La Tabla 2 describe las zonas con más alto puntaje ( 5 y 6 ), de acuerdo con los índices utilizados.

\section{Tabla 2}

Resumen de las variables incluidas en Análisis LISA, territorios que cumple 5 a 6 condiciones

\begin{tabular}{|c|c|c|c|c|c|}
\hline & Santiago oriente & Santiago poniente & Santiago norte & Santiago sur & Independencia \\
\hline $\begin{array}{l}\text { Condiciones no } \\
\text { cumplidas }\end{array}$ & - & Valor del suelo & Valor del suelo & Uso mixto & Valor del suelo \\
\hline Valor suelo & $28 \%$ & $23 \%$ & $20 \%$ & $27 \%$ & $25 \%$ \\
\hline Densidad & 272 hab./ha & 48 hab./ha & 62 hab./ha & 71 hab./ha & 136 hab./ha \\
\hline ISMT & $10 \%$ & $9 \%$ & $7 \%$ & $5 \%$ & $6 \%$ \\
\hline Hacinamiento & $-19 \%$ & $-28 \%$ & $-28 \%$ & $-12 \%$ & $-21 \%$ \\
\hline Edad & $-21 \%$ & $13 \%$ & $18 \%$ & $11 \%$ & $-21 \%$ \\
\hline Escolaridad & $30 \%$ & $18 \%$ & $19 \%$ & $20 \%$ & $12 \%$ \\
\hline Materialidad & $5 \%$ & $9 \%$ & $4 \%$ & $0 \%$ & $7 \%$ \\
\hline $\begin{array}{l}\text { Superficie destino } \\
\text { mixto }\end{array}$ & $2001 \mathrm{~m}^{2}$ & $1367 \mathrm{~m}^{2}$ & $951 \mathrm{~m}^{2}$ & $0 \mathrm{~m}^{2}$ & $1299 \mathrm{~m}^{2}$ \\
\hline $\begin{array}{l}\text { Número máximo de } \\
\text { pisos }\end{array}$ & 21 pisos & 25 pisos & 17 pisos & 11 pisos & 25 pisos \\
\hline
\end{tabular}

Fuente: Elaboración propia en base a los Censos de Población y Vivienda 2002 y 2017 del Instituto Nacional de Estadísticas, la base de Permisos de Edificación 2012 a 2017 del Instituto Nacional de Estadísticas y la Estimación del Valor del Suelo realizada por el Observatorio de Ciudades UC. 


\section{Resultados}

De estas cinco zonas se seleccionan dos para la siguiente etapa de análisis visual. Primero, Santiago oriente, polígono que abarca las calles 10 de Julio, Portugal, Argomedo y Vicuña Mackenna, por ser el único que cumple con el puntaje máximo. Segundo, Independencia polígono situado en la comuna del mismo nombre, delimitado por las calles Gamero, Vivaceta, San Luis e Independencia, por tratarse del polígono más alejado de la clusterización. La Tabla 3 caracteriza ambas zonas.

La selección de ambas zonas no apuntó a buscar un contraste entre ellas, sino que buscaba analizar la continuidad en la transformación en dos zonas diferentes del centro y pericentro de la ciudad de Santiago.

\section{Tabla 3}

Tabla descriptiva de las zonas seleccionadas para el estudio

\begin{tabular}{|c|c|c|}
\hline & Santiago oriente & Independencia \\
\hline Promedio de personas en el hogar & 1,8 personas & 2,2 personas \\
\hline Valor del suelo & $34 \mathrm{UF} / \mathrm{m}^{2}$ & $22 \mathrm{UF} / \mathrm{m}^{2}$ \\
\hline Superficie & 8,5 & 33,5 \\
\hline Densidad & 342,8 hab./ha & 231,3 hab./ha \\
\hline Edad promedio jefe(a) de hogar & 36,6 años & 40,8 años \\
\hline Escolaridad promedio & 16,3 años & 15,1 años \\
\hline \multicolumn{3}{|l|}{ Lugar de residencia hace 5 años } \\
\hline En esta comuna & $37 \%$ & $43 \%$ \\
\hline Otra comuna & $43 \%$ & $32 \%$ \\
\hline Otro país & $19 \%$ & $25 \%$ \\
\hline \multicolumn{3}{|l|}{ Lugar de nacimiento } \\
\hline En esta comuna & $9 \%$ & $9 \%$ \\
\hline Otra comuna & $67 \%$ & $46 \%$ \\
\hline Otro país & $22 \%$ & $45 \%$ \\
\hline \multicolumn{3}{|l|}{ Países de nacimiento } \\
\hline Perú & $2 \%$ & $24 \%$ \\
\hline Venezuela & $10 \%$ & $9 \%$ \\
\hline Colombia & $4 \%$ & $6 \%$ \\
\hline Haití & $1 \%$ & $2 \%$ \\
\hline Argentina & $1 \%$ & $1 \%$ \\
\hline Bolivia & - & $1 \%$ \\
\hline Ecuador & - & $1 \%$ \\
\hline Otros países del Caribe & $1 \%$ & $1 \%$ \\
\hline Otros países de Europa & $2 \%$ & - \\
\hline Otros países de Sudamérica & $1 \%$ & - \\
\hline
\end{tabular}

Fuente: Elaboración propia en base a datos INE y SII. 


\section{Las zonas elegidas}

Santiago oriente. Según vemos en la Figura 2 Santiago oriente tiene una superficie de 8,5 hectáreas y una densidad 342,8 hab./ha. El valor del metro cuadrado es de $34 \mathrm{UF} / \mathrm{m}^{2}$ y en los hogares están compuestos en promedio por 1,8 personas.

\section{Figura 2}

\section{Mapa Santiago oriente e Independencia}

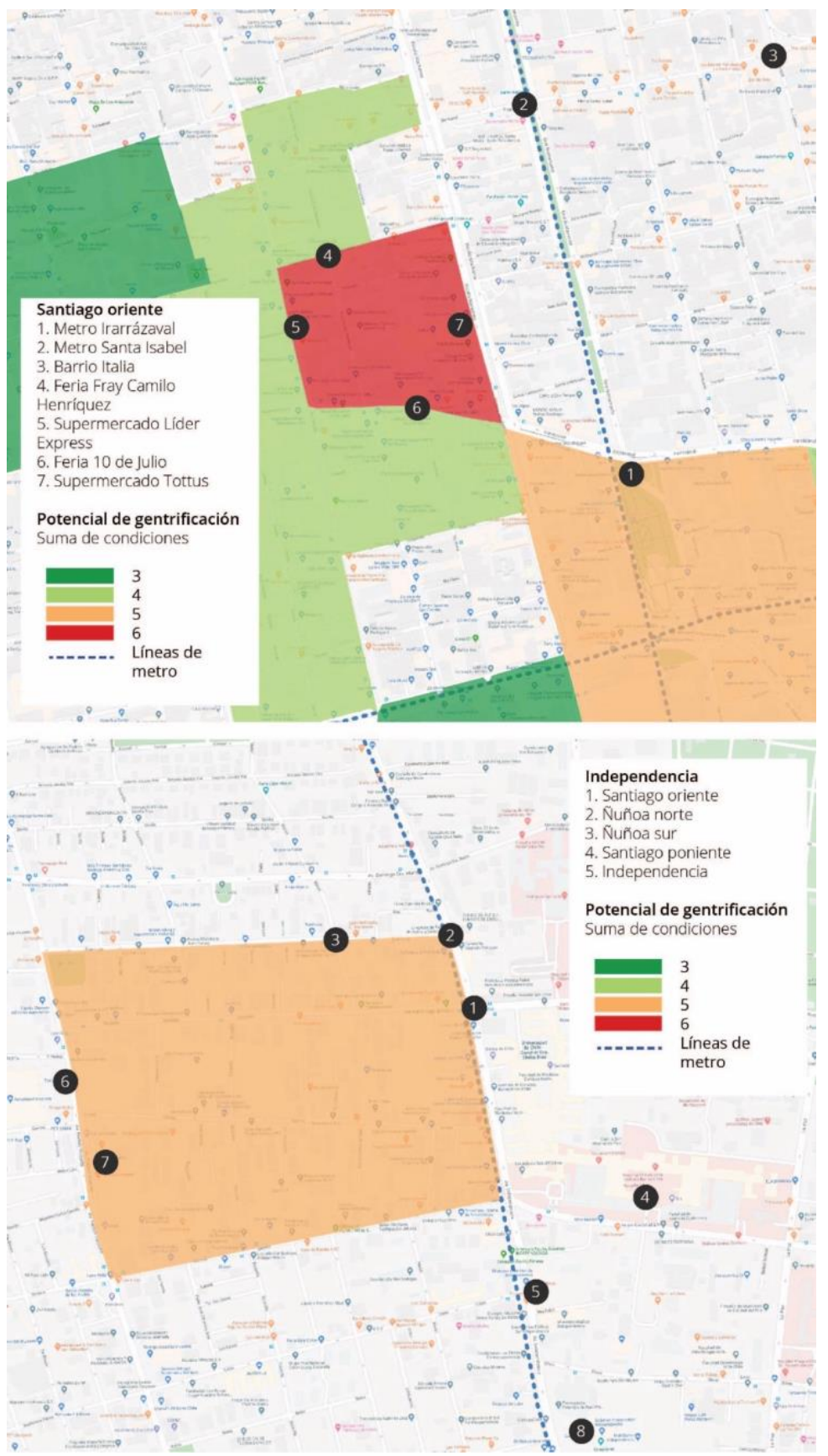

Fuente: Elaboración propia en base a los Censos de Población y Vivienda 2002 y 2017 del Instituto Nacional de Estadísticas, la base de Permisos de Edificación 2012 a 2017 del Instituto Nacional de Estadísticas y la Estimación del Valor del Suelo realizada por el Observatorio de Ciudades UC. 
A nivel socioeconómico, la edad promedio del jefe(a) de hogar es de 36,6 años, quien en promedio tiene 16,3 años de escolaridad.

En materia migratoria, el $22 \%$ nació en otro país, porcentaje que está compuesto por un $10 \%$ de migrantes venezolanos, $4 \%$ de migrantes colombianos, $4 \%$ de migrantes peruanos y $2 \%$ de migrantes europeos.

La Figura 2 también muestra que esta zona se encuentra próxima a dos líneas -Línea 3 y Línea 5- y dos estaciones del Metro -Irarrázaval y Santa Isabel-.

Independencia. Esta comuna considera 33,5 ha, con un valor del suelo de $22 \mathrm{UF} / \mathrm{m}^{2}$. La densidad de la zona es de 231,3 hab./ha y sus hogares tienen, en promedio, un tamaño de 2,2 personas.

Socioeconómicamente la edad promedio del jefe o jefa de hogar es de 40,8 años, con una escolaridad promedio de 15,1 años.

En esta zona la migración internacional alcanza un 45\% de sus hogares, porcentaje compuesto principalmente por migrantes peruanos (24\%), seguido por Venezuela (9\%) y Colombia (6\%).

La Figura 2 muestra esquemáticamente la zona Independencia, la cual tiene en sus cercanías la nueva estación Hospitales de la Línea 3 del Metro.

\section{Los cambios materiales del barrio}

A través del contraste de registros fotográficos se pudieron distinguir seis tendencias, las cuales dan forma a las transformaciones urbanas, propias de estos barrios. Estas tendencias que se registraron permiten ilustrar cómo se ha ido produciendo el cambio en el entorno construido entre 2012 y 2019 en ambos barrios.
Estas seis tendencias, sin embargo, son elementos analíticos, lo que implica que no puedan entrecruzarse entre ellos. Es relevante plantear también que, al considerar ambos barrios seleccionados, existe una clara diferencia entre ellos. Mientras Santiago oriente presenta un proceso más claro de transformación, Independencia aún se encuentra en una etapa temprana, a pesar de que presenta elementos reconocibles.

Las seis tendencias recogidas son:

- Cambio de giro comercial

- Paso de uso habitacional a uso comercial

- Aumento del comercio de menor escala

- Aumento del comercio migrante

- Instalación de las grandes superficies comerciales

- Sofisticación del comercio

Cambio de giro comercial. Locales que previamente se dedicaban a un rubro comercial en particular, son renovados para cambiar el giro comercial y ofrecer productos completamente diferentes.

El caso más emblemático es el del Kiosko Roca (Figura 3), cuya propuesta gastronómica, ligada con la ciudad de Punta Arenas, viene a reemplazar a la tradicional Librería El Sol, aunque mantiene la estética nostálgica del lugar.

Otro caso interesante es el de una pequeña avícola ubicada en Carrión (Figura 3 ), la cual se volvió multicolor para vender confites. Vemos también los locales comerciales de la Figura 3 , que muestran cómo un restaurante pasó a convertirse en una veterinaria y tienda para mascotas, y una distribuidora de confites en una farmacia alternativa a las grandes cadenas. 


\section{Figura $3^{6}$}

De arriba a abajo: Kiosko Roca, Av. Irarrázaval con Av. Vicuña Mackenna, Santiago oriente; Confitería Makarena, Calle Carrión, Independencia; Locales comerciales, Av. Vicuña Mackenna, Santiago oriente.
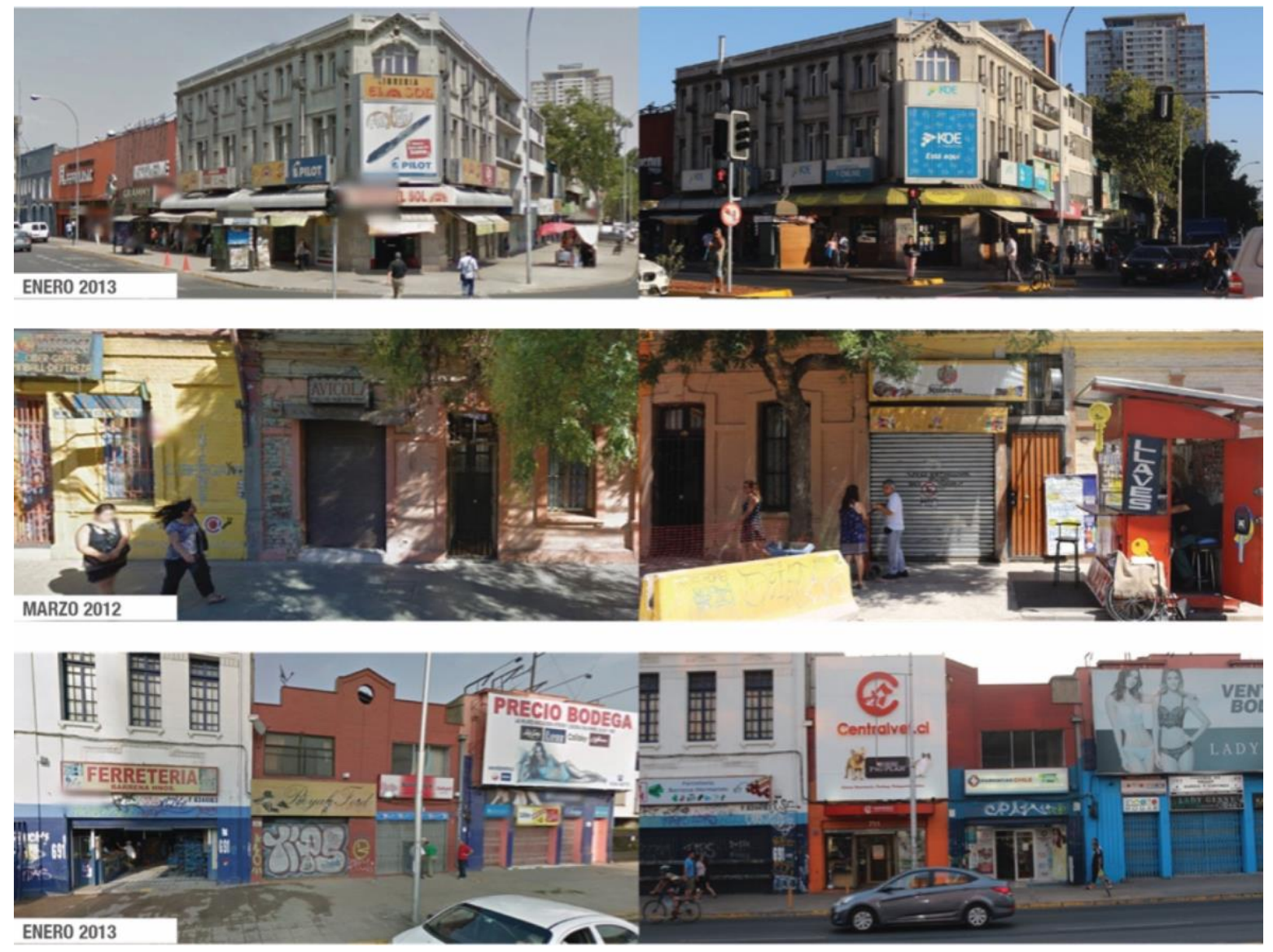

Fuente: Elaboración propia en base a imágenes de Google Street View.

Paso de uso habitacional a uso comercial. Se aprecian transformaciones más drásticas donde viviendas son renovadas para ser utilizadas con uso comercial.

Dos ejemplos claros se encuentran en la Calle Argomedo de Santiago. El primero es el de una casa de fachada continua que es convertida en una tienda para mascotas o pet store (Figura 4), como se aprecia en su letrero. El segundo es la reconversión de una casona en una guardería (Figura 4).

\footnotetext{
${ }^{6}$ En todas las imágenes comparativas presentadas, la fotografía de la derecha fue tomada en enero 2019.
} 


\section{Figura 4}

De arriba abajo: El Arca Pet Store, Calle Argomedo, Santiago oriente; Jardín Infantil Entreniños, Calle Argomedo, Santiago oriente.
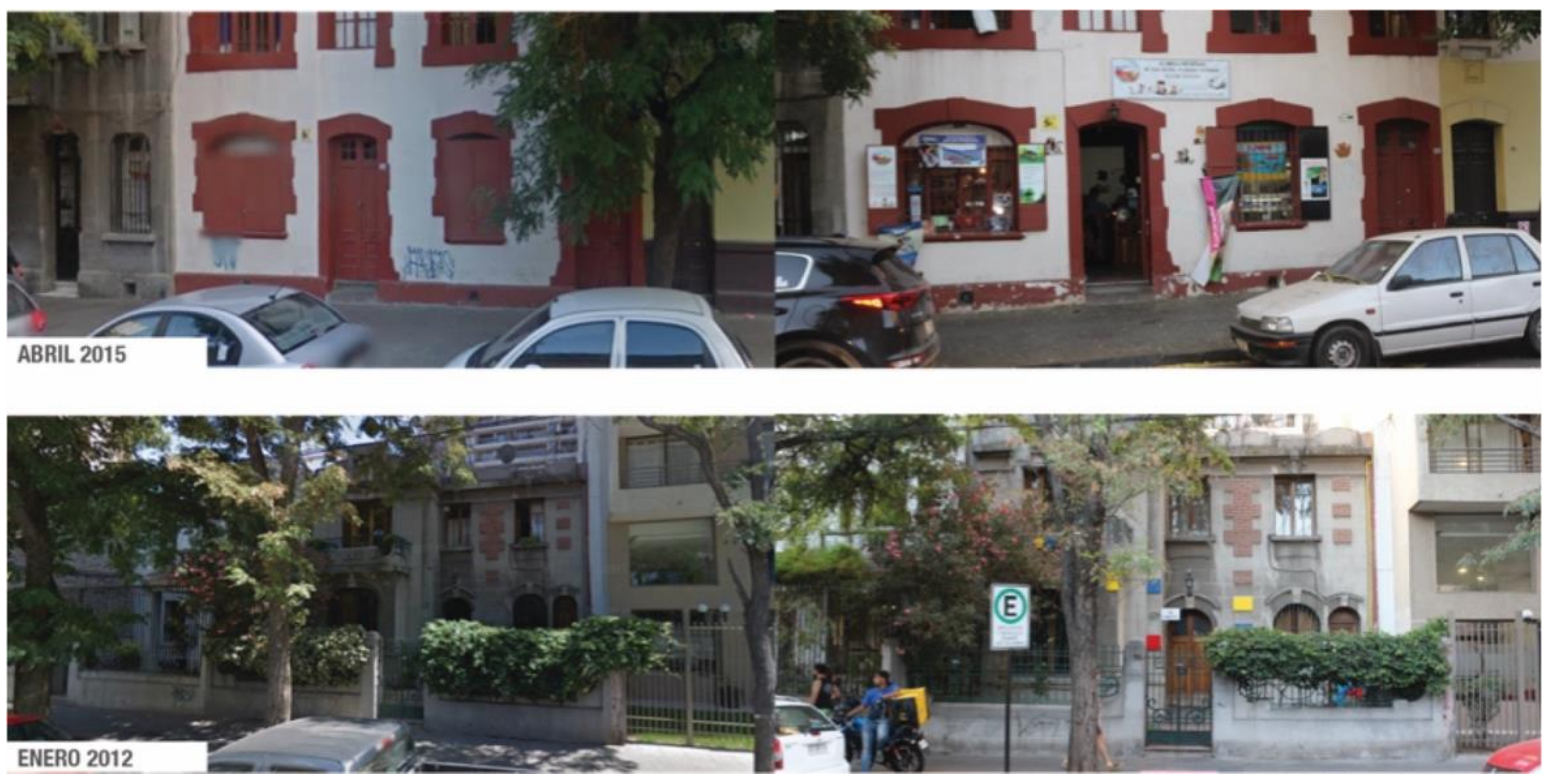

Fuente: Elaboración propia en base a imágenes de Google Street View

Aumento del comercio de menor escala. Se trata del tipo de comercio que más se ha multiplicado en el barrio (Figura 5). Sus principales estrategias son el aumento de la variedad de su oferta, principalmente la de productos vinculados con la migración latinoamericana que se ha asentado en el barrio: harina para arepas, distintos tipos de empanadas, chicha venezolana, plátanos verdes, entre otros.

\section{Figura 5}

\section{Minimarket, Fray Camilo Henríquez, Santiago oriente}

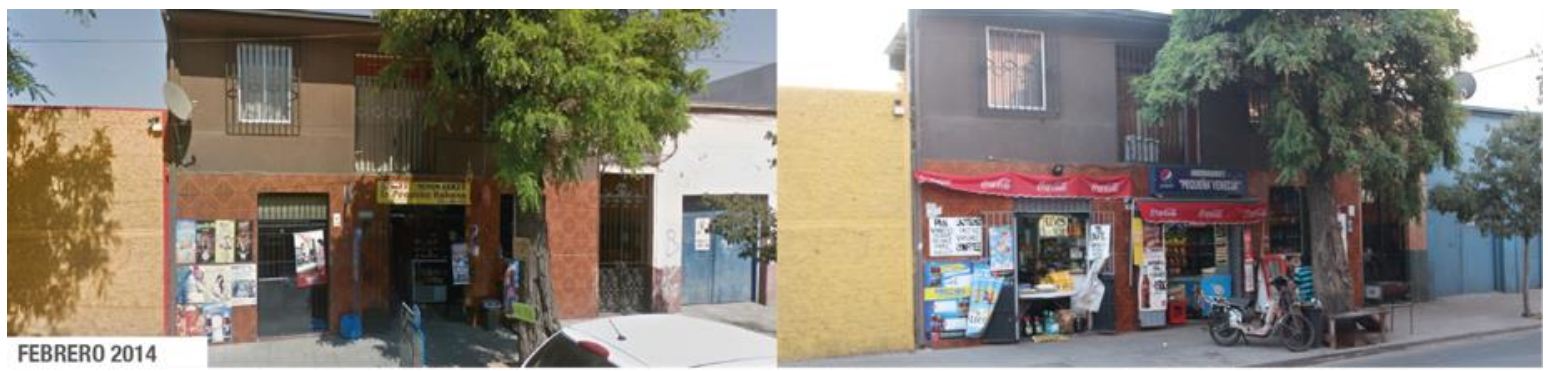

Fuente: Elaboración propia en base a imágenes de Google Street View. 
Aumento del comercio migrante. La escala de este comercio (Figura 6) también es pequeña y el cambio pasa principalmente por el tipo de productos ofrecidos, cuya variedad viene dada por el ingreso de productos o servicios que no sólo responden a la demanda de las comunidades de migrantes que se asientan en el barrio, ellos también vienen a sincretizarse con la demanda nacional. A diferencia de lo que ocurre con los minimarkets, donde muchos de los dueños son autóctonos, pero quienes atienden son migrantes, en las peluquerías y barberías, es donde se presencia el mayor ingreso de lo que podrías denominar al migrante "emprendedor".

\section{Figura 6}

\section{Barbería venezolana, Portugal, Santiago oriente}

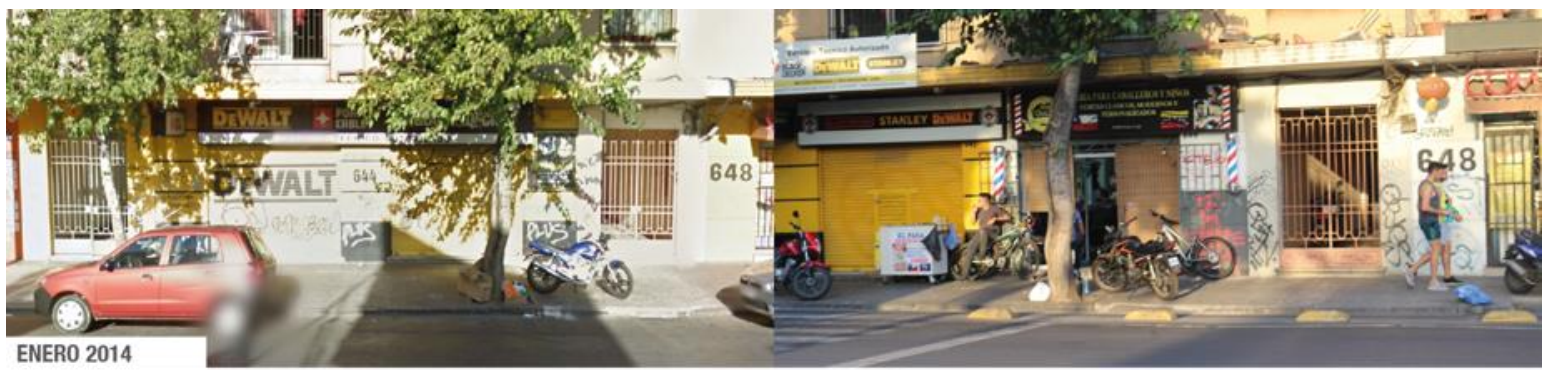

Fuente: Elaboración propia en base a imágenes de Google Street View.

Instalación de las grandes superficies comerciales. Si bien es el de mayor escala y, por ende, el más intrusivo para el contexto barrial, este tipo de comercio (Figura 7) mantiene códigos conocidos y aunque representa una amenaza para la forma en que tradicionalmente se concibe la relación cliente-locatario en un barrio, este formato colabora en la economía doméstica, debido a sus menores precios relativos. 


\section{Figura 7}

De arriba abajo: Supermercado, Avenida Portugal, Santiago oriente. Supermercado Tottus, Av. Vivaceta, Independencia
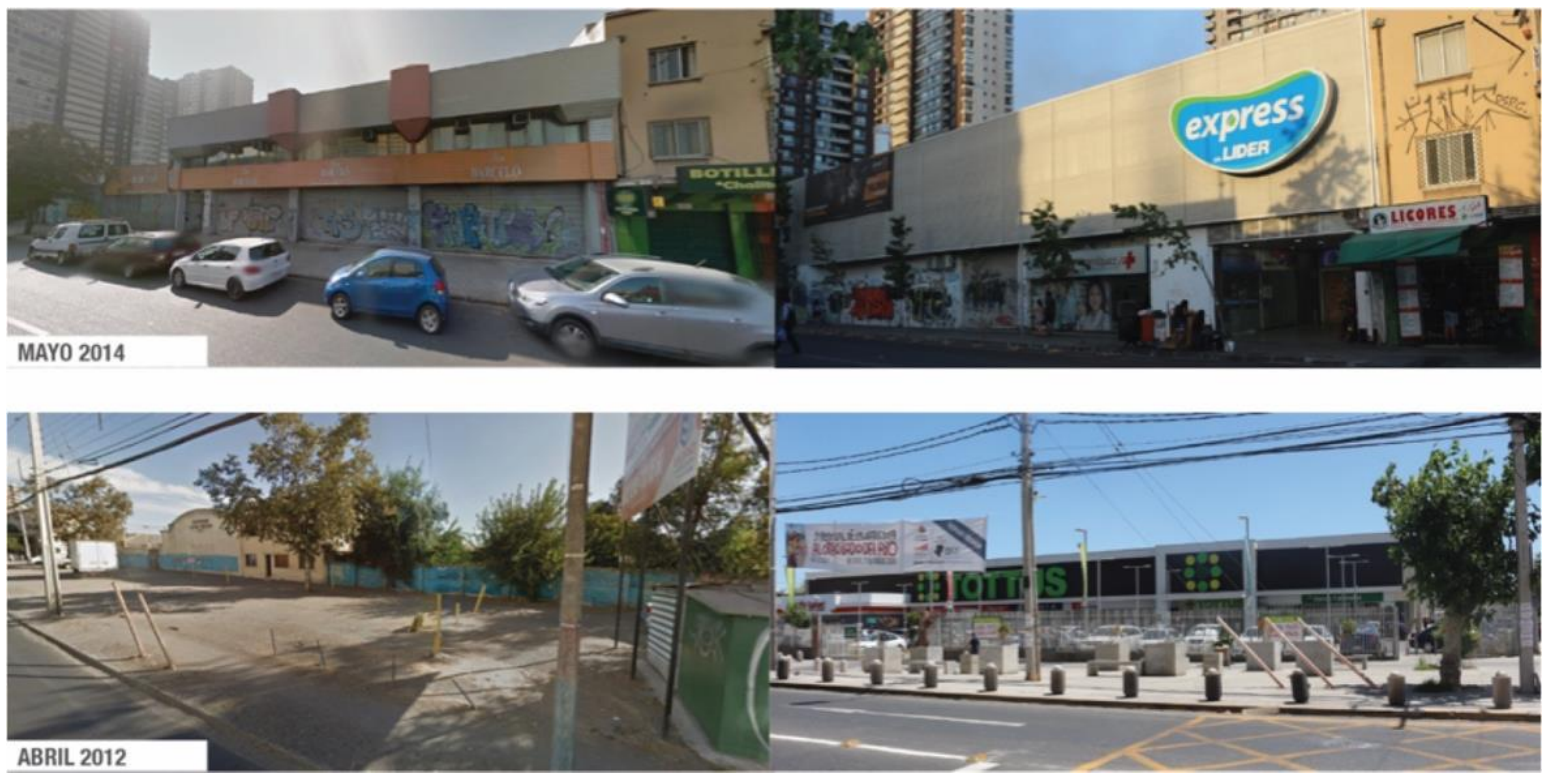

Fuente: Elaboración propia en base a imágenes de Google Street View.

Sofisticación del comercio. Este tipo de comercio tiende a mantener una escala reducida y es, probablemente, el último en llegar, y se caracteriza por el cambio tanto en la oferta como en los aspectos estéticos, puntos claves que diferencian a este tipo de comercio y lo alejan del comercio de barrio habitual. En esta categoría también se encuentra la oferta gastronómica renovada y con un toque gourmet.
Este tipo de comercio además introduce claros patrones de embellecimiento, que se traduce en la recuperación de espacios arquitectónicos (Figura 8) o el uso de coloridos murales comisionados que renuevan las fachadas de tiendas (Figura 8). 


\section{Figura 8}

De arriba abajo: Mural en pinturería, Avenida 10 de julio, Santiago oriente; Placa comercial, Argomedo, Santiago oriente; Bar Restaurante, Argomedo, Santiago oriente
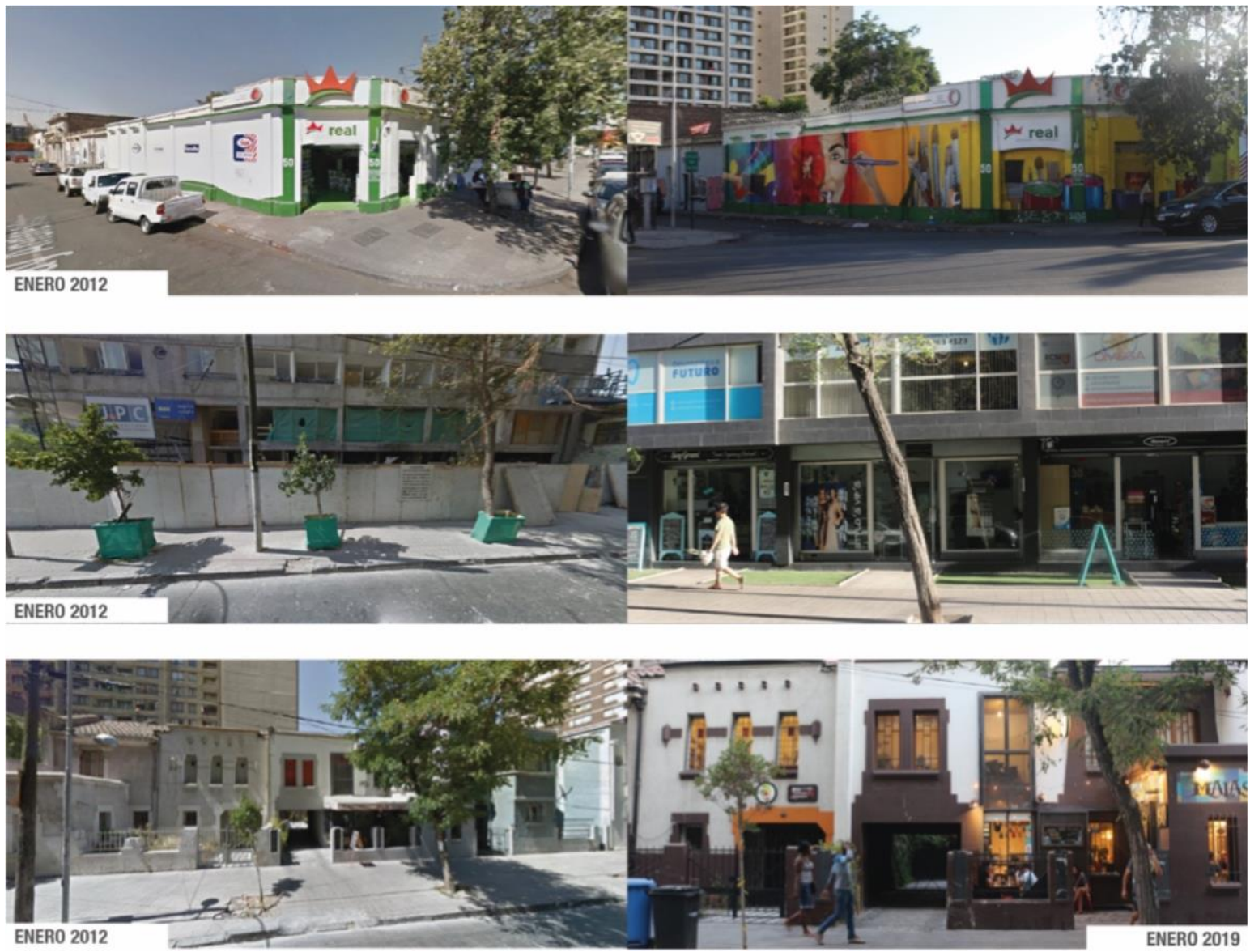

Fuente: Elaboración propia en base a imágenes de Google Street View.

\section{Gentrificación comercial como gentrificación superdiversa}

El proceso de gentrificación en los barrios analizados no se entiende simplemente como un proceso que transforma el comercio del barrio. Los espacios comerciales han vivido una rápida transformación, se habita una nueva escala y nuevos códigos que hacen transitar a estos espacios urbanos hacia nuevas materialidades y en este camino estarían contribuyendo al proceso de acumulación por desposesión del hábitat.

Un elemento clave de este proceso es que no puede ser disociado del proceso de superdiversificación que reconfigura los espacios urbanos en conjunto con el proceso de gentrificación. La gentrificación se nutre de la diversidad y la diversidad ve en la gentrificación un aliado desde el cual construir ciudad bajo códigos que se han vuelto reconocibles en todo el mundo, pero que se criollizan en el espacio urbano santiaguino (González \& Waley, 2013; Zukin et al., 2016).

De esta forma, se puede comenzar a pensar en la gentrificación del centro y pericentro de Santiago como una gentrificación superdiversa. Lo que estaría mostrando que no sólo la escala del fenómeno es distinta a la que se aprecia en el Norte Global, debido a la intervención de los agentes inmobiliarios (López-Morales, 2013), sino también que se alimenta de los proceso migratorios que 
proveen de elementos de diversidad cultural, los cuales estarían transformando también el comercio local en los barrios centrales de Santiago.

\section{Conclusiones}

La presente investigación buscaba introducirse en la investigación de la transformación barrial de la mano del comercio y el consumo, indagando en procesos de gentrificación comercial, superdiversidad y migración, como un desplazamiento que opera cambiando el entorno construido, proceso que está en la base de la acumulación por desposesión del hábitat. Este proceso queda inscrito en el espacio construido y constituye las bases para entender procesos de cambio más profundo que operan a nivel simbólico y de prácticas en los espacios comerciales, y en los barrios en los que ellos están inscritos.

Es difícil pronosticar si en el centro y pericentro de la ciudad se producirá la consolidación de la gentrificación comercial, del comercio migrante o un híbrido súper- diverso de ambos. Se ofrecen al análisis desde los estudios urbanos, sin embargo, espacios urbanos que responden a nuevas lógicas de transformación y que permiten complejizar la comprensión de la transformación urbana en el contexto de Santiago de Chile.

Adicionalmente se colabora en comprender el proceso de gentrificación desde un análisis que involucre la complejidad de los procesos urbanos, expandiendo su significado más allá de los procesos experimentados por espacios como el Barrio Italia, o de entender a la gentrificación ligada simplemente con la pérdida de la vivienda, sino también como la pérdida del hábitat, entendiendo al barrio desde el acceso al consumo que él debiera proveer.

Como hemos mencionado, restan las siguientes etapas, en las cuales se espera abordar estos fenómenos desde aspectos simbólicos y desde las prácticas, y cómo ella se transforman [R

\section{Referencias}

Andresen, M. A. (2011). Estimating the probability of local crime clusters: The impact of immediate spatial neighbors. Journal of Criminal Justice, 39(5), 394-404. https://doi.org/10.1016/j.jcrimjus.2011.05.005

Anselin, L. (2010). Local Indicators of Spatial AssociationLISA. Geographical Analysis, 27(2), 93-115. https://doi.org/10.1111/j.1538-4632.1995.tb00338.x

Casgrain, A., y Janoschka, M. (2013). Gentrificación y resistencia en las ciudades latinoamericanas El ejemplo de Santiago de Chile. Andamios, Revista de Investigación Social, 10(22), 19. https://doi.org/10.29092/uacm.v10i22.265

Clark, E. (2005). The Order and Simplicity of Gentrification-A Political Challenge. En Gentrification in a Global Context (pp. 261-269). Routledge, Taylor \& Francis Group.

Colodro, U. (2017). La gentrificación comercial, ¿un proceso de activación del espacio público urbano?: Los casos de Santiago (Chile) y Seúl (Corea del Sur). Entretextos, 9(26), 47-57.
Contraloría General de la República. (2014). Informe Investigación Especial (No 3). Contraloría General de la República. Recuperado de http://transparencia.ine.cl/auditorias/informe 3.pdf

Freedland, J. (2005, julio 15). The World in One City. The Guardian. https://www.theguardian.com/uk/2005/jul/15/july7. uksecurity 9

Glass, R. (1964). London: Aspects of Change. MacGibbon $\&$ Kee.

Gonzalez, S. (2017). Contested markets, contested cities: Gentrification and urban justice in retail spaces (1 Edition). Routledge.

Gonzalez, S., \& Waley, P. (2013). Traditional Retail Markets: The New Gentrification Frontier? Antipode, 45(4), 965-983. https://doi.org/10.1111/j.14678330.2012.01040.x

Hall, S. (2009). Being at Home: Space for Belonging in a London Caff. Open House International, 34(3), 81-87.

Hall, S. (2012). City, street and citizen: The measure of the ordinary. Routledge. 
Hall, S. (2013). The politics of belonging. Identities, 20(1), 46-53. https://doi.org/10.1080/1070289X.2012.752371

Hall, S., Finlay, R., \& King, J. (2018). The Migrant Street. En The SAGE Handbook of the 21st Century City (pp. 464-477). SAGE Inc.

Harvey, D. (2005). The new imperialism (1. issued as paperback). Oxford Univ. Press.

Hiebert, D., Rath, J., \& Vertovec, S. (2015). Urban markets and diversity: Towards a research agenda. Ethnic and Racial Studies, 38(1), 5-21. https://doi.org/10.1080/01419870.2014.953969

Hubbard, P. (2017). The Battle for the High Street. Palgrave Macmillan UK. https://doi.org/10.1057/9781-137-52153-8

Hwang, J., \& Sampson, R. J. (2014). Divergent Pathways of Gentrification: Racial Inequality and the Social Order of Renewal in Chicago Neighborhoods. American Sociological Review, 79(4), 726-751. https://doi.org/10.1177/0003122414535774

INE. (2017a). Cuestionario Censo 2017. Recuperado de https://redatamine.ine.cl/cuestionarios/CVP2017.pdf

INE. (2017b). Web Diseminación Censo 2017. Recuperado de https://resultados.censo2017.cl/Region?R=R13

INE. (2018). Características sociodemográficas de la inmigración internacional en Chile (Censo 2017) [Síntesis de Resultados]. Recuperado de https://www.ine.cl/docs/defaultsource/demogr\%c3\%a1ficas-yvitales/inmigraci\%c3\%b3n/s\%c3\%adntesis.pdf?sfvrsn $=795659 \mathrm{~d} 24$

Janoschka, M. (2016). Gentrificación, desplazamiento, desposesión: Procesos urbanos claves en América Latina. Revista INVI, 31(88), 27-71. https://doi.org/10.4067/s0718-83582016000300002

Lees, L. (2000). A reappraisal of gentrification: Towards a 'geography of gentrification'. Progress in Human Geography, 24(3), 389-408. https://doi.org/10.1191/030913200701540483

Lees, L. (2012). The geography of gentrification: Thinking through comparative urbanism. Progress in Human Geography, 36(2), 155-171. https://doi.org/10.1177/0309132511412998
López-Morales, E. (2013). Gentrificación en Chile: Aportes conceptuales y evidencias para una discusión necesaria. Revista de Geografía Norte Grande, (56), 31-52. https://doi.org/10.4067/S071834022013000300003

López-Morales, E. (2015). Gentrification in the global South. City, 19(4), 564-573. https://doi.org/10.1080/13604813.2015.1051746

López-Morales, E., Shin, H. B., \& Lees, L. (2016). Latin American gentrifications. Urban Geography, 37(8), 1091-1108. https://doi.org/10.1080/02723638.2016.1200335

Loukaitou-Sideris, A., Gonzalez, S., \& Ong, P. (2017). Triangulating Neighborhood Knowledge to Understand Neighborhood Change: Methods to Study Gentrification. Journal of Planning Education and Research, 39(2), 227-242. https://doi.org/10.1177/0739456X17730890

Marcuse, P. (1985). Gentrification, Abandonment, and Displacement: Connections, Causes, and Policy Responses in New York City. Urban Law Annual; Journal of Urban and Contemporary Law, 28(1), 195240.

We Made That LSE Cities. (2017). High Streets for all. Greater London Authority. https://www.london.gov.uk/sites/default/files/high_s treets for all report web final.pdf

Mincer, J. (1974). Schooling, experience, and earnings. National Bureau of Economic Research, Columbia University Press.

Moons, E., Brijs, T., \& Wets, G. (2008). Hot Spot Analysis: Improving a Local Indicator of Spatial Association for Application in Traffic Safety. En Computational Science and Its Applications -ICCSA 2008 (pp. 221231). Springer.

Observatorio de Ciudades UC. (s. f.). Metodología OCUC ISMT. sin publicar.

Observatorio Social. (2017). Archivo histórico de Encuesta Casen-Vivienda. http://observatorio.ministeriodesarrollosocial.gob.cl/ casen/casen def vivienda.php

Rivera, M. y Orozco, H. (2014). Gentrificación comercial en Santiago Centro. Recuperado de https://es.scribd.com/document/243897958/GENTRI FICACION-COMERCIAL-EN-SANTIAGO-CENTRO-Maite$\underline{\text { Rivera-y-Hernan-Orozco-pdf }}$ 
Rojo, F. (2016). La gentrificación en los estudios urbanos: Una exploración sobre la producción académica de las ciudades. Cadernos Metrópole, 18(37), 697-719. https://doi.org/10.1590/2236-9996.2016-3704

Sabatini, F., Rasse, A., Cáceres, G., Robles, M. S., y Trebilcock, M. P. (2017). Promotores inmobiliarios, gentrificación y segregación residencial en Santiago de Chile. Revista Mexicana de Sociología, 79(2), 229260. Recuperado de http://www.scielo.org.mx/scielo.php?script=sci artte xt\&pid=S0188-25032017000200229\&lng=es\&tlng=es

Smith, N. (2002). New Globalism, New Urbanism: Gentrification as Global Urban Strategy. Antipode, 34(3), 427-450. https://doi.org/10.1111/14678330.00249

Vertovec, S. (2007). Super-diversity and its implications. Ethnic and Racial Studies, 30(6), 1024-1054. https://doi.org/10.1080/01419870701599465

Wessendorf, S. (2014). Commonplace Diversity: Social Relations in a Super-Diverse Context. Palgrave Macmillan UK. https://doi.org/10.1057/9781137033314
Yanasmayan, Z. (2011). Concepts of Multiculturalism and Assimilation. En Interculturalism. Europe and its Muslims in Search of Sound Societal Models (pp. 1727). Centre for European Policy Studies.

Zukin, S. (2005). Point of purchase: How shopping changed American culture (1st paperback ed). Routledge.

Zukin, S. (2008). Consuming Authenticity: From Outposts of Difference to Means of Exclusion. Cultural Studies, 22(5), 724-748. https://doi.org/10.1080/09502380802245985

Zukin, S. (2010). Naked City: The Death and Life of Authentic Urban Places. Oxford University Press.

Zukin, S., Kasinitz, P., \& Xiangming, C. (Eds.). (2016). Global cities, local streets: Everyday diversity from New York to Shanghai (1 Edition). Routledge, Taylor \& Francis Group 